\title{
Sexual structure of a highly reproductive, recovering gorgonian population: quantifying reproductive output
}

\author{
Roberta Cupido ${ }^{1,5, *}$, Silvia Cocito ${ }^{1}$, Valentina Manno ${ }^{2}$, Sara Ferrando ${ }^{2}$, \\ Andrea Peirano ${ }^{1}$, Mimmo Iannelli ${ }^{3}$, Lorenzo Bramanti ${ }^{4}$, Giovanni Santangelo ${ }^{5}$ \\ ${ }^{1}$ ENEA Marine Environment Research Centre, PO Box 224, La Spezia 19100, Italy \\ ${ }^{2}$ Dip.Te.Ris, V. Benedetto XV 5, Genoa 16132, Italy \\ ${ }^{3}$ Department of Mathematics, University of Trento, V. Sommarive 14, Povo (Trento) 38123, Italy \\ ${ }^{4}$ Institut de Ciencias del Mar (CSIC), Passeig Marítim de la Barceloneta 37-49, Barcelona 08003, Spain \\ ${ }^{5}$ Department of Biology (Zoology), University of Pisa, via A. Volta 6, Pisa 56126, Italy
}

\begin{abstract}
A population of the Mediterranean red gorgonian Paramuricea clavata has exhibited unexpected resilience after being impacted by 2 anomalous mortality events in 1999 and 2003. To understand the recovery mechanisms, we examined the population reproductive structure and reproductive output based on data collected via non-destructive sampling techniques. The overall population sex ratio was balanced, though the spatial distribution of sexes was significantly segregated. Dividing the population into 14 size classes on the basis of their measured average annual growth revealed a decreasing monotonic trend of abundance of larger classes. The Recruitment class was consistently dominant. The minimum size at first reproduction was $8.5 \mathrm{~cm}$ in height, corresponding to an age of $\sim 3 \mathrm{yr}$. The percentage of fertile colonies increased with size, reaching $90 \%$ in size Class 9 . Polyp fecundity increased with colony size and did not differ significantly between healthy and damaged colonies. As the number of mature oocytes produced by a colony is a function of polyp fecundity and of the number of reproductive polyps, colony reproductive output increased exponentially with size. The population reproductive output $\left(145 \times 10^{3}\right.$ mature oocytes $\mathrm{m}^{-2} \mathrm{yr}^{-1}$ ) was one-fifth of that measured in stable, undamaged populations and came mainly from the medium size classes. After the catastrophic mortality, the population has been recovering, albeit with reduced reproductive output. Moreover, it has exhibited a 2 -fold increase in recruitment rate, 3 -fold greater than that measured in other, undisturbed populations. Our findings are consistent with a strict density-dependent recruitment control operating in crowded, stable P. clavata populations.
\end{abstract}

KEY WORDS: Mass mortality · Northwestern Mediterranean · Octocorals · Paramuricea clavata · Population recovery $\cdot$ Fecundity tables

Resale or republication not permitted without written consent of the publisher

\section{INTRODUCTION}

Global climate change is having increasing effects on sublittoral communities, in particular on populations of benthic, sessile species (Garrabou et al. 2009, Lejeusne et al. 2010). A demographic approach can be used to assess both the status and growth trends of impacted populations (Santangelo et al. 2007, Linares \& Doak 2010). Knowledge of basic demographic features is thus essential for evaluating the extent and persistence of delayed effects on damaged populations as well as any cascade effects on community and ecosystem resilience (Lejeusne et al. 2010). Unfortunately, our knowledge in this regard is 
still rather limited, even for the major structuring and habitat-forming benthic species (Teixido et al. 2009, Edmunds 2010).

In recent years, repeated anomalous mortality events, co-occurring with anomalous temperature increases, have affected benthic, circalittoral suspension feeders in the rocky shores of the NW Mediterranean (Cerrano et al. 2000, Coma et al. 2009, Garrabou et al. 2009, Crisci et al. 2011). Particularly hard-hit were the gorgonians, which are habitatforming and structuring species within the circalittoral Mediterranean subtidal rocky-shore communities (Gili \& Coma 1998, Ballesteros 2006, Scinto et al. 2009, Cerrano et al. 2010, Tsounis et al. 2010). Changes in gorgonian population structure could lead to profound changes in the entire community. A better knowledge of gorgonian demographic structure and dynamics before and after such anomalous mortality events can shed some much needed light on the response of marine populations and communities to global climate change-induced changes (Linares et al. 2007b, 2008a).

Gorgonians are generally defined as species exhibiting low population dynamics with low, episodic recruitment rates (Gotelli 1988, Lasker 1991, Linares et al. 2007b). However, when subjected to overharvesting or mass mortality, which selectively affect larger colonies (Garrabou et al. 2001, Cerrano et al. 2005, Santangelo et al. 2007, Cupido et al. 2008, Huete-Stauffer et al. 2011), the persistence of their populations could in large measure depend on sexual reproduction (Linares et al. 2007b, Linares \& Doak 2010). Under such conditions, reproductive rates, generally considered to have limited influence on long-term gorgonian dynamics, could become important factors in determining the recovery and recolonization capacity of local populations. In particular, recruitment rate, a key factor in population growth rate, depends to a varying extent on population reproductive output, larval settlement and settler survival. Reproductive output is determined by the fertility, sex ratio, fecundity, size/age structure and density of each population (Santangelo et al. 2003). In modular invertebrates, such as gorgonians, the reproductive output of a colony is determined by both the number of the reproductive modules, which increases exponentially with colony size, and the fertility and fecundity of each module (Jackson \& Hughes 1985, Babcock 1991, Coma et al. 1995b). In isolated populations, larval settlement is controlled by larval supply and/or population density as well as by other factors external to the population (Grigg 1988, Caley et al. 1996).
The present study focuses on the reproductive features of a population of the Mediterranean red gorgonian Paramuricea clavata (Risso, 1826). As this population lives just below the edge of the summer thermocline, it was heavily impacted by the 2 mass mortality events affecting the NW Mediterranean during late summer 1999 and 2003. The anomalous mortality, associated to an abnormal sinking of the summer thermocline below its usual depths (Coma et al. 2009), reduced colony density by $78.3 \%$ (the highest mortality ever reported for this species), damaging the remaining colonies and shifting the dominant class of the population toward smaller sizes (Cupido et al. 2008). In the years following the events, the population showed positive growth rates and a recruitment rate 2 -fold greater than the pre-mortality values (Cupido et al. 2009a). In contrast to other gorgonians (Lasker et al. 1998), P. clavata is an external brooder, in which sexual reproduction is dominant in its life cycle. Thus, a sound knowledge of its reproductive features is basic to understanding the recovery dynamics of its populations.

As episodic mass mortality may have prolonged effects on Paramuricea clavata populations (Mistri \& Ceccherelli 1994); we therefore aimed to quantify the reproductive parameters and determine whether any delayed effects of the past mortality events still persist, after $6 \mathrm{yr}$, in the damaged population. Because the studied population is small in size and was impacted quite heavily, this study is based on mostly non-destructive sampling and measurement techniques. The data examined in the present study were collected from fixed plots, which enabled us to assess colony growth rate by measuring the same specimens over a number of years, to estimate mortality by following the fate of individual colonies and to identify newly settled colonies for each year (Recruitment). The overall aim of the present work was to assess the role that sexual reproduction plays in the recovery of impacted populations of this species. To this end, we have undertaken to (1) determine the population size structure in terms of classes based on the mean annual colony growth rate, (2) assess size (and age) at first reproduction and the fertility and fecundity of polyps and colonies of the different classes, (3) compile population fecundity tables and estimate the reproductive output and annual oocyte per recruit ratio (i.e. the probability that each mature oocyte becomes a recruit) of the impacted population and (4) compare these findings with the available pre-mortality data on this population, as well as with those previously recorded on other P. clavata populations. 


\section{MATERIALS AND METHODS}

\section{Sampling}

This study was conducted on the western side of the Gulf of La Spezia $\left(44^{\circ} 01^{\prime} \mathrm{N}, 09^{\circ} 50^{\prime} \mathrm{E}_{\text {; }}\right.$ Ligurian Sea, Italy), at Tinetto Island $\left(44^{\circ} 01^{\prime} 26^{\prime \prime} \mathrm{N}, 09^{\circ} 51^{\prime}\right.$ $\left.03^{\prime \prime} \mathrm{E}\right)$ and at Tinetto Shoal $\left(44^{\circ} 01^{\prime} 23^{\prime \prime} \mathrm{N}, 09^{\circ} 51^{\prime}\right.$ $05^{\prime \prime} \mathrm{E}$ ), on a population living between 17 and $25 \mathrm{~m}$ depth that was affected by the mortality events that occurred in late summer 1999 and 2003 in the NW Mediterranean (Garrabou et al. 2009). A detailed description of the studied area has been previously reported (Cupido et al. 2008, 2009a).

Due to its limited size $\left(\sim 1000 \mathrm{~m}^{2}\right)$ and to avoid any further damage to the population, all sampling was carried out by photographs and direct measurements taken in the field. Only when it was absolutely necessary (i.e. for sexual analyses), small $(\sim 3 \mathrm{~cm})$ segments of apical branches were collected. Twelve $1 \mathrm{~m}^{2}$ plots were fixed and examined yearly over 3 yr (June 2007 to June 2009) in 2 locations (6 plots at Tinetto Island and 6 at Tinetto Shoal) that were a few hundred meters apart. All of the colonies (including Recruitment) in each plot were mapped and numbered on a plastic sheet to enable re-identification in subsequent surveys. It was thus possible to determine the percentage of colonies exhibiting positive growth. Colonies were grouped into 3 categories: healthy, slightly damaged ( $<50 \%$ surface damage) and heavily damaged ( $>50 \%$ surface damage). Maximum height (i.e. the distance between the colony base and the longest branch tip) was measured with a ruler to the nearest $\mathrm{mm}$.

The variability of colony growth between 2 different years (2 levels: 2007 to 2008 and 2008 to 2009) and 2 different size groups ( 2 levels: colonies $<16 \mathrm{~cm}$ and $>16 \mathrm{~cm}$ ) was tested by a balanced 2-way orthogonal analysis of variance (ANOVA) with 40 replicates randomly selected among all of the colonies measured (showing both positive or negative growth). All of the colonies (except Recruitment) sampled in 2009 were divided into size classes according to the mean annual colony growth rate measured. Recruitment included all new colonies found on plots in May 2009, just before spawning.

\section{Fertility, sex ratio and sexual maturity}

Sex identification was performed on freshly collected, $3 \mathrm{~cm}$ long apical branch fragments under the dissecting microscope. To confirm colony sex deter- mination, histological analyses were also performed. Samples were fixed in $4 \%$ paraformaldehyde in phosphate-buffered saline solution (PBS, pH 7.4) for 6 to $12 \mathrm{~h}$, rinsed in PBS, decalcified (to eliminate calcite spicules) for $12 \mathrm{~h}$ at room temperature $(1: 100$ Osteodec, Bio-Optica), rinsed in tap water and partially dehydrated (up to $70 \% \mathrm{w} / \mathrm{v}$ ethanol) through successive passages in a graded ethanol series $(15$, 30 and $50 \%$ ).

Samples were later processed by ethanol standarddehydration series and embedded in Paraplast. Dewaxed $4 \mu \mathrm{m}$ polyp transverse sections were haematoxylin and eosin (H\&E) stained to determine colony sex.

Spawning events occurred in 2 distinct episodes: at the end of June and at the end of July. At the beginning of June 2008, 1 apical branch was collected from each of 205 colonies (>5 cm high) and fixed in $4 \%$ formalin-seawater solution. Ten polyps were dissected from each apical branch, and the gonads were examined. Colonies that did not present gonads were considered sterile. A $\chi^{2}$ test was performed to check any divergence from a balanced sex ratio (1:1).

The spatial distribution pattern of colony sex (i.e. sex segregation) was examined on a subsample of labelled and mapped mature colonies $(n=50)$ whose sex had been determined previously (as described above). Sex segregation was tested by an ad hoc $\chi^{2}$ test on the nearest-neighbour sex frequency (Upton \& Fingleton 1985). The null hypothesis was that the frequency of nearest neighbours of the same sex would not diverge from that in a random distribution. Nearest-neighbour analysis (Pielou 1962), measuring the frequency of nearest neighbours belonging to the same sex or not, enabled the assessment of any potential spatial segregation between sexes.

The size/age class at which colonies reached sexual maturity and the percentage of fertile colonies and polyps in each class were also determined.

\section{Female polyp fecundity}

To determine female polyp fecundity, 60 apical branches were collected from colonies that were $>5 \mathrm{~cm}$ in height in June 2008, just before oocyte release. Ten polyps per colony were then dissected, all of the oocytes were counted, and their average diameter was measured. Only oocytes $>200 \mu \mathrm{m}$ were considered mature (Coma et al. 1995a). To evaluate whether all mature oocytes were released during spawning, 30 female colonies were sampled 
shortly after the last spawning in 2008, which occurred on 25 July, and the number of oocytes per polyp (fecundity) and their diameters were calculated. The effects on polyp fecundity of the factors colony size (4 height classes: 6-15, 16-25, 26-35 and 36-45 cm) and damage (2 levels: healthy and heavily damaged) were checked on 32 fertile female colonies (replicates) by 2 -way orthogonal ANOVA.

Fecundity was measured only on apical polyps, assuming half of the fecundity of polyps belonging to higher order branches (Coma et al. 1995b).

\section{Female colony reproductive output}

A total of 30 female colonies were photographed with a Nikon D80 digital underwater camera equipped with an $80 \mathrm{~mm}$ lens and positioned perpendicular to the colony fan. A plastic $2 \times 2 \mathrm{~cm}$ gridded board was placed behind the colony. Only planar colonies were chosen for this analysis as highly 3-dimensional structures do not allow for making reliable measurements of total colony length on photographs. Photographs were processed by Sigmascan ${ }^{\mathrm{TM}}$ image analysis software. The total colony length and the number and length of all apical branches were measured. Polyp density was determined on 30 randomly chosen $1 \mathrm{~cm}$ branch fragments.

As the apical branches (Order I) and all of the other branches (order $>$ I; according to the classification of Beiring \& Lasker 2000) yielded different fecundity rates (Coma et al. 1995b), the colony reproductive outputs of the different size classes $\left(b_{i}\right)$ were calculated as the sum of the birth coefficient of the apical branches $\left(b_{\mathrm{ab}}(i)\right)$ and the birth coefficient of all the other branches $\left(b_{\mathrm{ob}}(i)\right)$, using the following equations:

$$
\begin{gathered}
b_{\mathrm{ab}}(i)=N_{\mathrm{ab}}(i) \times Q_{\mathrm{ap}}(i) \times L_{\mathrm{ab}} \times D_{\mathrm{p}} \\
b_{\mathrm{ob}}(i)=Q_{\mathrm{op}}(i) \times L_{\mathrm{ob}}(i) \times D_{\mathrm{p}}
\end{gathered}
$$

where $N_{\mathrm{ab}}(i)$ is the average number of apical branches in each size class, $Q_{a p}(i)$ is the average fecundity of apical polyps in each size class, $L_{\mathrm{ab}}$ is the average length of apical branches, $D_{\mathrm{p}}$ is the average polyp density (polyp $\mathrm{cm}^{-1}$ ), $Q_{\mathrm{op}}(i)$ is the average fecundity of polyps of the other branches in each size class, and $L_{\mathrm{ob}}(i)$ is the average total length of non-apical branches for a colony in size class $i$.

The average number of fertile apical polyps $\left(N_{\text {ap }}(i)\right)$ was calculated by multiplying the average number of apical branches by the average apical-branch length and the average density of fertile polyps:

$$
N_{\mathrm{ap}}(i)=N_{\mathrm{ab}}(i) \times L_{\mathrm{ab}} \times D_{\mathrm{p}}
$$

The average number of fertile polyps of all of the other branches $\left(N_{\mathrm{op}}(i)\right)$ was calculated by multiplying the average total length of all of the other branches $\left(L_{\mathrm{ob}}(i)\right)$ by the density of fertile polyps:

$$
N_{\mathrm{op}}(i)=L_{\mathrm{ob}}(i) \times D_{\mathrm{p}}
$$

As the extent of injury negatively impacts the number of reproductive polyps and consequently the colony reproductive output, we assumed a colony gonadal production of 75 and $25 \%$ of that of healthy colonies for the slightly damaged and heavily damaged colonies, respectively $(<50 \%$ and $>50 \%$ surface damage; Cupido et al. 2008).

\section{Fecundity table}

All of the main population reproductive parameters have been summarised in a fecundity table (see Table 1; see Stearns 1997 for information on the construction of fecundity tables). The population was divided into size classes, and the average number of fertile female colonies in each size class was calculated using the equation

$$
X_{\mathrm{f}(i)}=X_{i} \times F_{i} \times \mathrm{SR}
$$

that is, by multiplying the number of colonies in each size class $\left(X_{i}\right.$, in number of colonies $\left.12 \mathrm{~m}^{-2}\right)$ by the percentage of fertile female colonies in each size class (fertility, $F_{i}$ ) and the sex ratio (SR). The class reproductive output $\left(b_{i} X_{f}(i)\right)$ was then calculated by multiplying the number of fertile female colonies in each size class $\left(X_{\mathrm{f}}(i)\right)$ by the average number of mature oocytes produced by a colony of size $i\left(b_{i}\right)$. Finally, by summing these values, the overall population reproductive output was obtained $\left(\sum b_{i} X_{f}(i)\right)$, which estimates the average number of mature oocytes produced yearly by all healthy and damaged colonies living in a $12 \mathrm{~m}^{2}$ area.

\section{RESULTS}

\section{Annual colony growth rate and population size structure}

No significant interannual variability in colony growth rate was found between the 2 periods examined (2007 to 2008 and 2008 to 2009) or between smaller $(<16 \mathrm{~cm})$ and larger $(>16 \mathrm{~cm})$ colonies $(2$-way ANOVA: factor period 2 levels, $\mathrm{p}>0.1$ non-signifi- 
cant [NS]; factor size 2 levels, $\mathrm{p}>0.1 \mathrm{NS}$; interaction, $\mathrm{p}=0.87 \mathrm{NS}_{i} \mathrm{~N}=40$ ). As the mean annual colony growth rate was $3 \pm 0.7 \mathrm{~cm} \mathrm{yr}^{-1}$ (mean \pm standard error, $\mathrm{n}=243$ ), we chose to divide the population into size classes distinguished by a $3 \mathrm{~cm}$ difference in height. As the majority ( $88 \%$ ) of $1 \mathrm{yr}$ colonies were $<4.5 \mathrm{~cm}$, this value was chosen as the growth rate of the first year of colony life. The majority of colonies exhibited positive growth $(92.8 \%)$; only a few healthy $(2.3 \%)$ and damaged colonies $(4.9 \%)$ yielded negative values due to the breakage of some branches. The population was thus made up of 14 classes (Fig. 1). The first class (Recruitment), including all newly settled colonies, exhibited the highest density ( 4.1 recruits $\mathrm{m}^{-2}$ ), accounting for $22 \%$ of all colonies. The number of colonies in the different classes exhibited a monotonic decreasing pattern (Fig. 1).

In 2009, the overall colony density (including healthy and damaged ones) was 17.9 colonies $\mathrm{m}^{-2}$ (about half of the 1998 pre-mortality density; Cupido et al. 2008); the damaged colonies accounted for $24 \%$ of the entire population, and the average injured surface area was $9.9 \%$. As a consequence of the 2 mass mortalities, the population's larger (and older) classes (Classes 11 to 14$)$ were quite scarce $(0.25$ colonies $\mathrm{m}^{-2}$, on average; Fig. 1). Accordingly, they were grouped together into a single, largest-sized class in the fecundity table (see Table 1).

\section{Sex ratio and size at sexual maturity}

Histological analyses were conducted to check macroscopic Paramuricea clavata colony sex identification: spherical gametes (pink, white or yellow) $>200 \mu \mathrm{m}$ in diameter, characterized by a solid consistency, were mature oocytes (Fig. 2a), while white gonads, spherical or irregular, with soft consistency, were spermatocysts (sperm sacs) (Fig. 2b).

The population sexual structure was completely gonochoric at both the colony and polyp level: none of the 173 fertile colonies (84.4\%) and none of the 1730 fertile polyps were hermaphroditic. Overall, 80 females and 93 males were found, yielding a sex ratio statistically consistent with $1: 1 \quad\left(1: 1.16, \chi^{2}=0.97\right.$, $\mathrm{df}=1, \mathrm{p}>0.05)$. The sterile colonies $(15.6 \%)$ consistently belonged to the smaller and younger classes $(<25 \mathrm{~cm})$.

The spatial distribution of colony sex, based on the sex of nearest neighbours (Pielou 1962), diverged significantly $\left(\chi^{2}=4.8, \mathrm{df}=1, \mathrm{p}<0.05\right)$ from that expected in a random distribution for a population

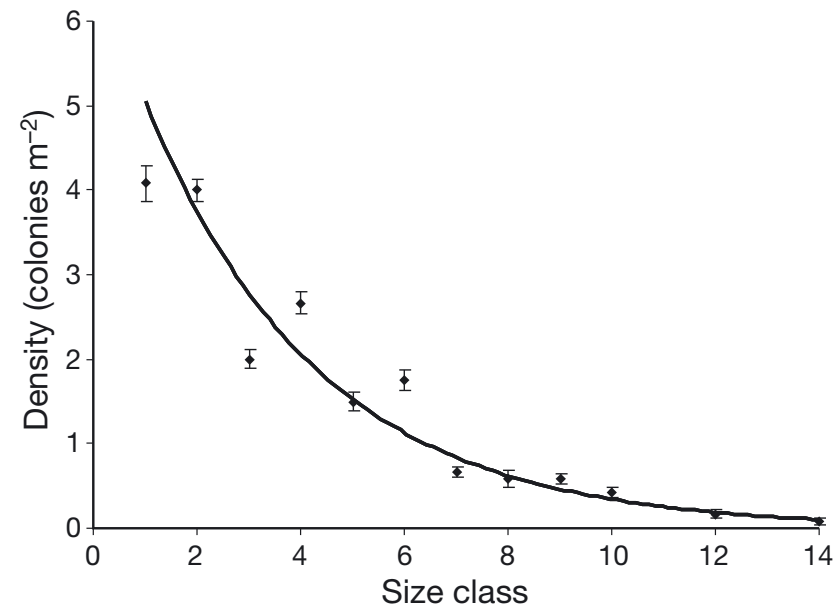

Fig. 1. Paramuricea clavata. Size structure of the La Spezia population in 2009. The density (mean $\pm \mathrm{SE}$ ) of colonies in the different size classes follows a monotonic decreasing pattern $\left(y=7.157 \mathrm{e}^{-0.32 x}, \mathrm{R}^{2}=0.944\right)$

with a balanced sex-ratio ( 0.5 probability of finding a same-sex nearest neighbour), suggesting that some segregation of different sex colonies likely occurred in the population.

The size (height) at first reproduction of females was $8.5 \mathrm{~cm}$, corresponding to size/age Class $3(20 \%$ of colonies were reproductive). In the higher classes, the percentage of mature colonies rose rapidly, reaching $90 \%$ in Class 9 (Fig. 3a). The percentage of fertile polyps also increased with size, reaching $100 \%$ fertility in Class 11.

\section{Female reproductive features}

Oocytes, ranging between 40 and $594 \mu \mathrm{m}$ (Fig. 3b), exhibited a clear-cut subdivision in 2 distinct size groups corresponding to 2 different cohorts. During spawning (mid-June) only oocytes $>200 \mu \mathrm{m}(379 \pm$ $67.6 \mu \mathrm{m}$, mean \pm standard deviation $[\mathrm{SD}], \mathrm{n}=3829$ ) were released, while the smaller ones (111.7 \pm $43.5 \mu \mathrm{m}, \mathrm{n}=712$; Fig. $3 \mathrm{~b}$ ) remained in the polyp gastrovascular cavity and would be released the following year (Coma et al. 1995a). Before spawning, the polyps of apical branches bear $17.3 \pm 9.0(\mathrm{n}=3829)$ larger, mature oocytes.

The following data on the oocytes are limited to the first (older) cohorts alone (those that would be spawned the same year as the sampling). The number of oocytes per polyp (i.e. polyp fecundity, $Q$ ) increased greatly with colony size from 0.08 oocytes polyp $^{-1}$ in the first reproductive class ( 3 yr) to 21.45 in the last (Classes 11 to 14 ; Fig. 4a, Table 1). Aver- 




Fig. 2. Paramuricea clavata. Mature polyps: (a-e) females; (f-h) males. $(\mathrm{a}, \mathrm{b}, \mathrm{c})$ Colour morphs of fresh mature oocytes surrounded by zona pellucida (arrow). (d,e) Haematoxylin-eosin (H\&E) stained histological sections of (d) mature oocytes; (e) sagittal section of gastrovascular cavity $(\mathrm{gc})$ and oocytes attached to the gametophoric stalk (arrow). (f) Fresh spermatocysts. $(g, h) H \& E$ stained histological sections of spermatocysts. (g) Spermatocyst attached to the gametophoric stalk (arrow head). A thin mesoglea layer (arrow) delimits the sperm sac. (h) Sagittal section of polyp gastrovascular cavity (gc) full of spermaries in different maturation stages

age polyp fecundity, also rapidly increasing with size, exhibited an asymptotic trend in the last class, suggesting that the maximum number of oocytes that each polyp can brood was reached (Fig. 4a). No statistical difference in polyp fecundity was found between healthy and heavily damaged colonies of the 4 size classes examined, while a highly significant difference was found among size classes (Table 2). This finding is consistent with the increase of fecundity with colony size reported below (next paragraph).

Polyp density was $34.5 \pm 7.9$ polyp $\mathrm{cm}^{-1}$, and the average length of apical branches was $2 \pm 0.13 \mathrm{~cm}$ (mean $\pm \mathrm{SD}, \mathrm{n}=1623$ ). The number of apical branches per colony increased considerably with colony size, ranging between 8 and 185 (Fig. 4b). Branches of order $>$ I accounted for one-third of total colony length (b, i.e. angular coefficient, $\sim 3: 2$ in the linear fit; Fig. $4 \mathrm{c}$ ). The mean number of polyps per colony increased exponentially with colony size (Fig. 5a), from 776 polyps for a colony in Class 2 to 12097 polyps for a colony in Class 10. The mean number of oocytes in the colonies of each class brood also increased exponentially with size (Fig. 5b, Table 1). However, this increase was attenuated by the increasing percentage of damaged colonies in the larger/older classes. 



Fig. 3. Paramuricea clavata. Sexual maturation of female colonies. (a) Percentage of fertile P. clavata colonies in the different size classes. $(\mathrm{b}, \mathrm{c})$ Distribution of oocyte size in $(\mathrm{b})$ June and (c) September; 2 cohorts in the former period (prespawning) and only 1 in the latter (post-spawning) could be identified

\section{Fecundity table}

Since healthy and damaged colonies did not differ significantly in either polyp fertility or fecundity, the same fecundity values were used to calculate the birth coefficient and colony reproductive output. Birth coefficients increased exponentially with colony size, varying by some orders of magnitude: Class 3 produced some tens of oocytes, whereas larger colonies produced several thousand mature oocytes (Fig. 5b, Table 1).

The overall estimated reproductive output of this population was $\sim 145000$ mature oocytes $\mathrm{m}^{-2}$. As the average recruitment density in this population was 4.1 recruits $\mathrm{m}^{-2}$ (Table 3 ), the eggs:recruit ratio was 35500:1. Slightly damaged colonies had a smaller number of reproductive modules than healthy ones. However, because such colonies were more numerous
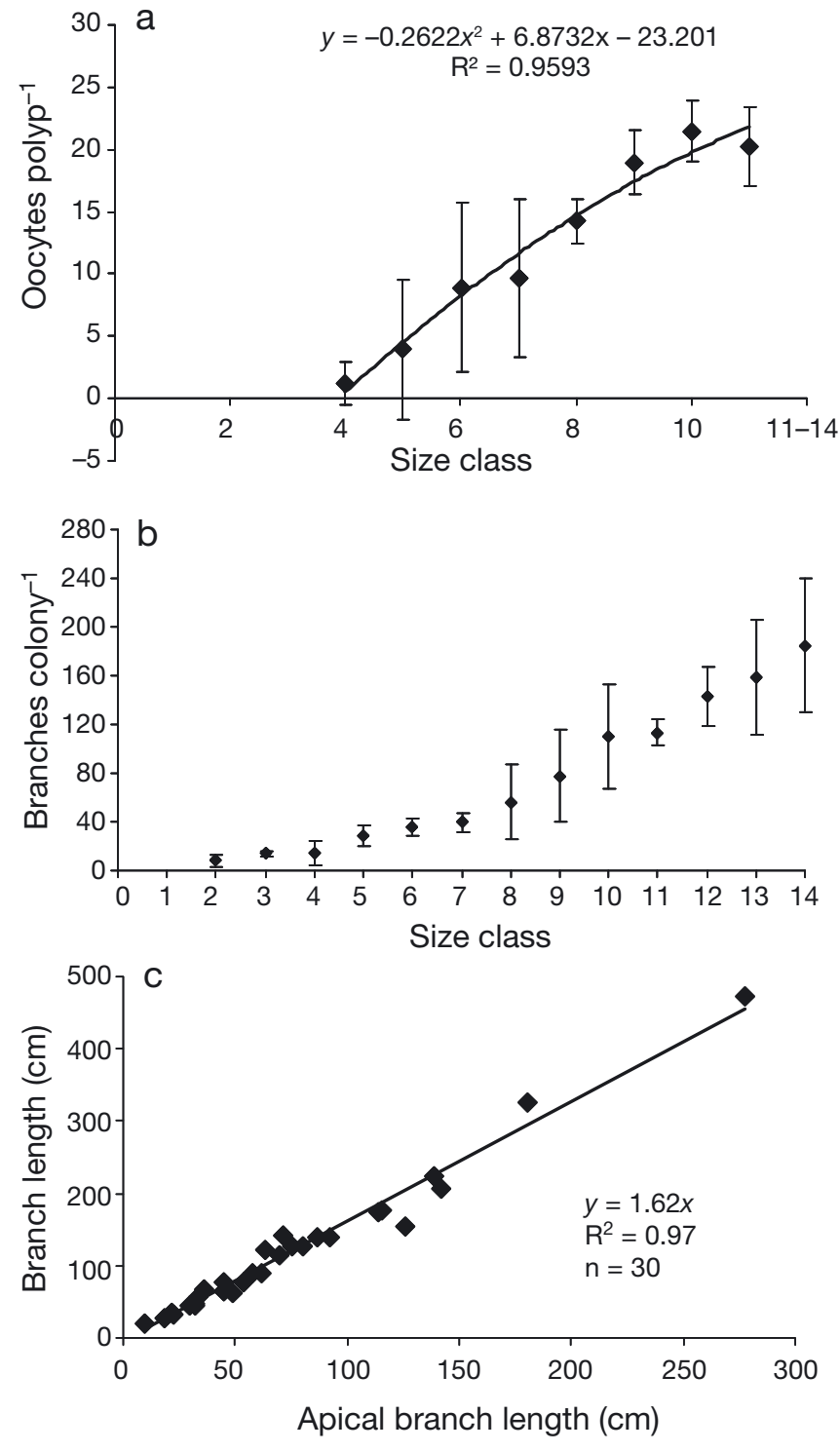

Fig. 4. Paramuricea clavata. Reproductive features of female colonies. (a) Average number of mature oocytes per apical polyp $\left(Q_{\mathrm{ab}}(i)\right.$ in Table 1$)$ in different size classes. (b) Number of apical branches in different size classes. (c) Total colony branch length and apical branch length. Error bars: 1 SE

and belong to larger, more fecund classes (Classes 1 to 4$)$, they accounted for about half of the overall population reproductive output ( 72000 mature oocytes $\mathrm{m}^{-2}$ ). In contrast, the total reproductive output of heavily damaged colonies was low $(\sim 1.6 \%)$ due to loss of a large part of the reproductive modules.

Most of the population reproductive output ( $77 \%)$ came from colonies in Classes 6 to $10(21.6 \%$ of the overall population), while Classes 11 to 14 , though comprising few larger colonies $(1.4 \%)$, accounted for $18.8 \%$. In contrast, despite their larger numbers $(77 \%)$, colonies in classes $<6$ accounted for only 
Table 1. Paramuricea clavata. Fecundity of the La Spezia population. For each size class (i): $X_{i}$ : density of colonies $\left(12 \mathrm{~m}^{2}\right)_{i} Q_{\mathrm{ap}}$ : female polyp fecundity of apical branches; $Q_{\mathrm{op}}$ : polyp fecundity of the other branches (order $>$ I); $N_{\text {ap }}$ : number of fertile polyps of apical branches; $N_{\text {op }}$ : number of fertile polyps of the other branches (order $>$ I); $F_{i}$ : percentage of fertile female colonies; $S R$ : sex ratio; $X_{\mathrm{f}}$ : number of fertile female colonies in each class; $b_{i}$ : birth coefficient (number of oocytes produced by each colony in the class) $b_{i} X_{\mathrm{f}}$ : overall number of mature oocytes

\begin{tabular}{|lccccccccccc|}
\hline Size class (cm) & Age class $(i)$ & $Q_{\mathrm{ap}}(i)$ & $Q_{\mathrm{op}}(i)$ & $N_{\mathrm{ap}}(i)$ & $N_{\mathrm{op}}(i)$ & $X_{i}$ & $S R$ & $F_{i}$ & $X_{\mathrm{f}}(i)$ & $b_{i}$ & $b_{i} X_{\mathrm{f}}(i)$ \\
\hline $0-4.5$ & 1 & 0 & 0 & 0 & 0 & 49 & - & 0 & 0 & 0 & 0 \\
$4.5-7.5$ & 2 & 0 & 0 & 518 & 259 & 48 & - & 0 & 0 & 0 & 0 \\
$7.5-10.5$ & 3 & 0.08 & 0.04 & 855 & 428 & 24 & 0.5 & 0.20 & 2.40 & 86 & 205 \\
$10.5-13.5$ & 4 & 1.21 & 0.61 & 944 & 472 & 32 & 0.5 & 0.50 & 8 & $14 \times 10^{2}$ & $12 \times 10^{3}$ \\
$13.5-16.5$ & 5 & 3.93 & 1.97 & $17 \times 10^{2}$ & 828 & 18 & 0.5 & 0.75 & 6.75 & $81 \times 10^{2}$ & $55 \times 10^{3}$ \\
$16.5-19.5$ & 6 & 8.90 & 4.45 & $22 \times 10^{2}$ & $11 \times 10^{2}$ & 21 & 0.5 & 0.84 & 8.82 & $24 \times 10^{3}$ & $211 \times 10^{3}$ \\
$19.5-22.5$ & 7 & 9.70 & 4.85 & $20 \times 10^{2}$ & $10 \times 10^{2}$ & 8 & 0.5 & 0.89 & 3.56 & $25 \times 10^{3}$ & $88 \times 10^{3}$ \\
$22.5-25.5$ & 8 & 14.25 & 7.13 & $29 \times 10^{2}$ & $15 \times 10^{2}$ & 7 & 0.5 & 0.94 & 3.29 & $52 \times 10^{3}$ & $170 \times 10^{3}$ \\
$25.5-28.5$ & 9 & 18.95 & 9.48 & $44 \times 10^{2}$ & $22 \times 10^{2}$ & 7 & 0.5 & 0.93 & 3.26 & $105 \times 10^{3}$ & $341 \times 10^{3}$ \\
$28.5-31.5$ & 10 & 21.45 & 10.73 & $81 \times 10^{2}$ & $40 \times 10^{2}$ & 5 & 0.5 & 1 & 2.5 & $216 \times 10^{3}$ & $541 \times 10^{3}$ \\
$>31.5$ & $11-14$ & 20.23 & 10.12 & $86 \times 10^{2}$ & $43 \times 10^{2}$ & 3 & 0.5 & 1 & 1.5 & $218 \times 10^{3}$ & $328 \times 10^{3}$ \\
Overall reproductive output $\left(12 \mathrm{~m}^{2}\right)$ & & & & & & & & & $1744 \times 10^{3}$ \\
Reproductive output (1 m $\left.\mathrm{m}^{2}\right)$ & & & & & & & & & $145 \times 10^{3}$ \\
\hline
\end{tabular}

Table 2. Paramuricea clavata. 2-way ANOVA comparing the effects of size (4 levels) and damage (2 levels) on colony fecundity $\left({ }^{* * *} \mathrm{p}<0.0001\right)$. ns: non-significant

\begin{tabular}{|lccccc|}
\hline Source & df & SS & MS & $F$ & $p$ \\
\hline Damage & 1 & 0.031 & 0.031 & 0.011 & $0.917(\mathrm{~ns})$ \\
Size & 3 & 1946.59 & 648.864 & 228.172 & $0^{* * *}$ \\
Damage $\times$ Size & 3 & 1.09 & 0.364 & 0.781 & $0.942(\mathrm{~ns})$ \\
Residual & 24 & 68.25 & 2.843 & & \\
\hline
\end{tabular}

$3.8 \%$ of the population reproductive output as they were smaller, less fecund and less fertile.

\section{DISCUSSION}

Since 1998, we have been studying the demographic history of a Paramuricea clavata population that was impacted by 2 anomalous mortality events in 1999 and 2003, and reportedly suffered the highest mortality ever recorded for this species (Cupido et al. 2008). In the years following such events, this population revealed an unexpectedly high capacity for recovery (Cupido et al. 2009b). To highlight the mechanisms leading to such dynamics, we examined its reproductive structure to quantify its reproductive output.

The studied population was gonochoric at both the colony and polyp level (like most Gorgonacea; Benayahu et al. 1989, Brazeau \& Lasker 1990, Coma et al. 1995a, Santangelo et al. 2003). The sex ratio did not deviate significantly from 1:1, in accordance with optimal resource allocation in populations with ran-
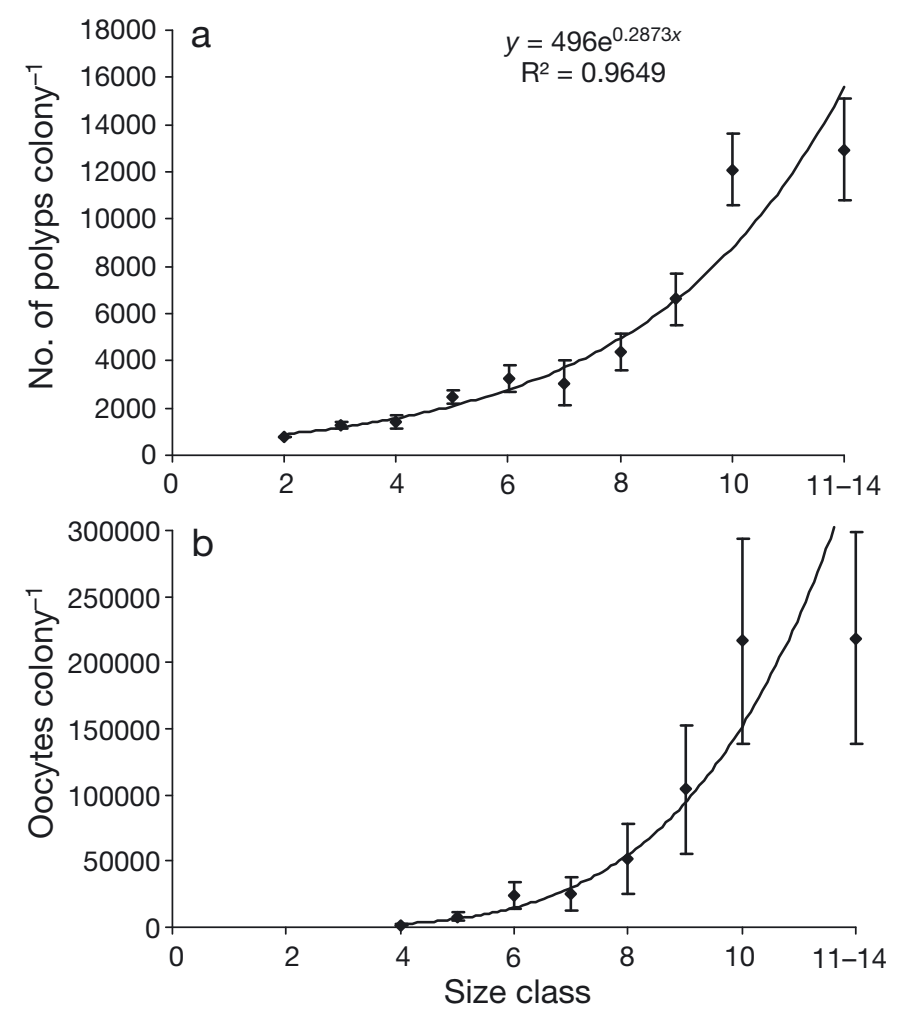

Fig. 5. Paramuricea clavata. Reproductive features of female colonies. (a) Mean number of polyps in the colonies belonging to the different size classes. (b) Reproductive output $\left(b_{i}\right.$ in Table 1) of different size classes. The curve was obtained by fitting the functions $Q_{\mathrm{ab}}(i)$ and $N_{\mathrm{ap}}(i)+N_{\mathrm{op}}(i)$ (Figs. $4 \mathrm{a}$ \& 5a). Error bars SE

dom mating (Leigh et al. 1985, Mari et al. 2008). Nevertheless, skewed sex ratios have been reported for some octocorals (Brazeau \& Lasker 1990), specifi- 
Table 3. Paramuricea clavata. Summary of the main demographic features of different $P$. clavata populations

\begin{tabular}{|c|c|c|c|c|c|c|c|}
\hline $\begin{array}{l}\text { Study area } \\
\text { and source }\end{array}$ & $\begin{array}{l}\text { Mass } \\
\text { mortality }\end{array}$ & $\begin{array}{l}\text { Sex-ratio } \\
\left.\text { (o vs. } 0^{7}\right)\end{array}$ & $\begin{array}{l}\text { Colony density } \\
\left(\text { colonies } \mathrm{m}^{-2}\right. \\
\text { mean } \pm \mathrm{SD})\end{array}$ & $\begin{array}{l}\text { Recruitment } \\
\left(\text { recruits } \mathrm{m}^{-2} \text { ) }\right.\end{array}$ & $\begin{array}{l}\text { Colony } \\
\text { growth rate } \\
\left(\mathrm{cm} \mathrm{yr}^{-1}\right)\end{array}$ & $\begin{array}{l}\text { Oocytes: } \\
\text { recruits }\end{array}$ & $\begin{array}{l}\text { Reproductive } \\
\text { output } \\
\text { (oocytes } \mathrm{m}^{-2} \text { ) }\end{array}$ \\
\hline \multicolumn{8}{|l|}{ La Spezia Gulf } \\
\hline Cupido et al. (2009a) & Pre-mortality & - & $33.7 \pm 3.2$ & $2.6 \pm 0.5$ & - & $1: 770000$ & 2000000 \\
\hline Present study & Post-mortality & $1: 1$ & $17.9 \pm 5.3$ & $4.1 \pm 4.7$ & $3 \pm 1.4$ & $1: 35000$ & 145000 \\
\hline \multicolumn{8}{|l|}{ Strait of Messina } \\
\hline Mistri \& Ceccherelli (1994) & - & - & $19.4 \pm 9.2$ & 0.5 & $2.7 \pm 1.6$ & - & - \\
\hline \multicolumn{8}{|l|}{ Medes Islands } \\
\hline Coma et al. (1995b) & - & $1: 1$ & 56 & - & - & - & 729000 \\
\hline Coma et al. (1998) & - & - & - & - & $1.8 \pm 1.3$ & - & - \\
\hline Coma et al. (2004) & & - & - & - & - & $1: 450000$ & - \\
\hline Gori et al. (2007) & - & $1: 1$ & - & - & - & - & - \\
\hline Linares et al. (2007a) & - & $1: 1$ & $42.8 \pm 2.4$ & $1.3 \pm 1.4$ & - & $1: 500000$ & - \\
\hline \multicolumn{8}{|l|}{ Portofino } \\
\hline Cerrano et al. (2005) & Pre-mortality & $1: 1$ & $10.8 \pm 3.2$ & $2.5 \pm 1.0$ & - & - & - \\
\hline Cerrano et al. (2005) & Post-mortality & $1: 3.3$ & $13.9 \pm 5.1$ & $4.8 \pm 2.9$ & $1.4 \pm 0.7$ & - & - \\
\hline \multicolumn{8}{|l|}{ Capo de Palos } \\
\hline Gori et al. (2007) & - & $1: 7$ & - & - & - & - & - \\
\hline \multicolumn{8}{|l|}{ Cap de Creus } \\
\hline Linares et al. (2007a) & - & $1: 1$ & $41.6 \pm 1.5$ & $1.5 \pm 1.0$ & - & & - \\
\hline
\end{tabular}

cally, some Paramuricea clavata populations (Cerrano et al. 2005, Gori et al. 2007; Table 3). As we found some significant segregation of sexes at a small spatial scale, we hypothesise that samplings of limited areas, covering only a few sexual patches, could have led to some of the skewed sex ratios reported. Further investigation is needed to clarify the mechanisms underlying such distribution and its effects on reproduction.

The plasticity of clonal organisms, capable of withstanding fragmentation, partial mortality and negative growth (Hughes \& Jackson 1985, Hughes \& Connell 1987, Babcock 1991, Rossi et al. 2011), could lead to complex demographic patterns and hence some 'distortion' of size-age relations. However, as we found a nearly constant colony growth rate over $2 \mathrm{yr}$ and for the different colony sizes, we divided the studied population into size classes on the basis of the mean annual colony growth rate. The annual colony growth found is consistent with that measured in the population living in the Messina Straits, an area subject to strong tidal streams (Mistri \& Ceccherelli 1994), a rate $\sim 2$-fold greater than that measured in the stable Medes population (Coma et al. 1998). We suggest that the high colony and population growth rates found could be related to the abundant organic matter (an important food source for Paramuricea clavata, according to Ribes et al. 1999) carried by the Magra River to the study area (Cupido et al. 2009a).
In the studied population, the earliest female reproduction occurred in small colonies $(8.5 \mathrm{~cm})$, corresponding to an approximate age of $3 \mathrm{yr}$, which is quite early considering the maximum life-span ( $50 \mathrm{yr}$; Weinberg \& Weinberg 1979) of this long-lived species (Linares 2006) and considerably earlier than that reported for the Medes population ( $7 \mathrm{yr}$ and $11 \mathrm{~cm}$ in height; Coma et al. 1995b).

As colony and polyp fertility and fecundity increased with size and age of colonies, confirming previous findings (Coma et al. 1995b), the contribution to the overall population reproductive output of the smallest colonies is generally quite low. However, when a population faces selective mortality of its larger colonies (Garrabou et al. 2001, Cerrano et al. 2005, Santangelo et al. 2007), precocious sexual maturity would increase population reproductive output and survival (Santangelo et al. 2003, Gallmetzer et al. 2010, Tsounis et al. 2010).

Assessing the main population reproductive parameters has enabled us to construct fecundity tables, which, by quantifying size/age-specific birth rates, allows extrapolations of population reproductive output (mature oocytes $\mathrm{m}^{-2}$ ). The resulting number of mature oocytes may overestimate the true larval output, though as a large portion of mature oocytes produce planulae (e.g. 61.9 to $68.6 \%$, Linares et al. 2008 b, or 93.3 to $97.3 \%$, Cupido 2010), this value may actually represent a reliable estimate. 
Colony reproductive output increased exponentially with size. This is due to the combined effects of 4 reproductive parameters, all of which increased with size: (1) percentage of fertile colonies, (2) number of apical branches, (3) percentage of mature polyps and (4) polyp fecundity. The higher mortality to which larger, highly reproductive individuals in the impacted Spezia population have been subjected (Cupido et al. 2009a) has evidently had a disproportionately negative effect on its reproductive output, which was $145 \times 10^{3}$ oocytes $\mathrm{m}^{2}, 5$-fold lower than in the stable Medes population (Coma et al. 1995b) and 14 -fold lower than that estimated for the pristine (in 1998) Spezia population $\left(2000 \times 10^{3}\right.$ oocytes $\left.\mathrm{m}^{-2}\right)$. Moreover, the medium-sized classes accounted for the greatest proportion of the overall reproductive output.

Anomalous mortality events may cause both immediate and delayed effects on reproduction, thereby reducing the fertility and fecundity of coral colonies and populations over time (Van Veghel \& Bak 1994). Under stress conditions, long-lived corals would presumably give priority to allocating energy to the recovery of dead tissue rather than to reproducing. Thus, a decrease in polyp fecundity seems to be a common pattern in recently damaged colonies (Michalek-Wagner \& Willis 2001). According to Linares et al. (2007a), within 2 yr of the 1999 mortality event, Paramuricea clavata female colonies showed a significant reduction in polyp fecundity. In the present study, however, the colonies, examined 6 yr after the 1999 and 2003 mortality events, did not seem to suffer from any long-lasting negative memory effects on their reproductive traits, given that polyps of healthy and damaged colonies showed statistically similar fecundity values. The only change found in the reproductive traits of damaged colonies was some fecundity reduction due to their lower number of polyps. These findings underline this P. clavata population's high capacity for recovery: after 2 dramatic mortality events, this population still exhibits abundant reproductive output, half of which comes from colonies that have been damaged.

Our findings confirm that Paramuricea clavata is one of the most highly reproductive gorgonians (the most reproductive, according to Torrents \& Garrabou 2011), as a large/old female colony can produce and release some tens of thousands of oocytes per year.

The recruitment density $6 \mathrm{yr}$ after the anomalous mortality events was 3- to 8-fold higher than that reported for other Paramuricea clavata populations (Mistri \& Ceccherelli 1994, Coma et al. 1998, Linares 2006, Linares et al. 2007b) and 100- to 2000-fold greater than those reported for other gorgonians (Gotelli 1988, Lasker 1991, Beiring \& Lasker 2000). The annual recruits:oocytes ratio in the studied population is $\sim 1: 35 \times 10^{3}$ compared to ratios ranging between $1: 450 \times 10^{3}$ and $1: 500 \times 10^{3}$ in the Medes population, in which a 5-fold higher reproductive output was recorded (Coma et al. 2004, Linares 2006, $2007 \mathrm{~b})$. In addition, given the limited dispersal capacity of gorgonian planulae together with the geographic isolation of the studied population, it seems safe to assume that only few oocytes could give rise to new colonies in other areas. This suggests that the majority of the reproductive output will be subject to an extremely rigorous local cut-off.

Moreover, although varying in different populations, the evident over-reproduction of Paramuricea clavata is likely a species strategy to consistently provide an abundant buffer of oocytes, only a small portion of which will become settlers as soon as there is new space available within the population. A mortality event selectively affecting larger/older colonies could foster recruitment by reducing the negative effect of the density of larger colonies on larval settlement (Bramanti et al. 2009). It is worth recalling that the only recruitment density comparable with that reported here (4.8 recruits $\mathrm{m}^{-2}$; Table 3 ) was found in a population similarly affected by mass mortality (Cerrano et al. 2005). Based on this, we can reasonably hypothesize that, as the stock of mature oocytes produced by the impacted population was still sufficiently large, the greater availability of space could have led to the increased recruitment encountered in the present study. Six years after the last mortality event, the affected population has reached a monotonic decreasing distribution of its size structure and now exhibits half of the pre-mortality density values. Moreover, although the population has fewer fertile polyps and a lower reproductive output due to prior mortality, its recruitment rate (over the 2007 to 2009 period) is 3 -fold greater.

Such findings are consistent with the self-thinning recruitment saturation model proposed for Paramuricea clavata populations (Linares 2006): whenever anomalous mortality upsets this stable state and density and biomass decrease, thereby increasing the available space, the population starts to recover through increased recruitment. The reproductive features examined here will be fundamental to our understanding of the future trajectories of populations subjected to mass mortality events. By using sizestructured matrix models, currently under development, the effective demographic limits to the recovery capacity of such populations can be assessed. 
Acknowledgements. R.C. was supported by an ENEA (Italian National Agency for New Technologies, Energy and Sustainable Economic Development) fellowship, M.I. and G.S. were funded by the Italian PRIN (Research Project of significant National Interest) 2007 project 200777BWEP, and L.B. was funded by a Marie Curie Intra-European Fellowship (CORGARD, Project No. 221072). We thank Fischer, Italy, for its economic support and A. Cafazzo for his revision of the English text.

\section{LITERATURE CITED}

Babcock RC (1991) Comparative demography of three species of scleractinian corals using age and size-dependent classifications. Ecol Monogr 61:225-244

Ballesteros E (2006) Mediterranean coralligenous assemblages: a synthesis of present knowledge. Oceanogr Mar Biol Annu Rev 44:123-195

Beiring EA, Lasker HR (2000) Egg production by colonies of a gorgonian coral. Mar Ecol Prog Ser 196:169-177

> Benayahu Y, Berner T, Achituv Y (1989) Development of planulae within a mesogleal coat in the soft coral Heteroxenia fuscescens. Mar Biol 100:203-210

Bramanti L, Iannelli M, Santangelo G (2009) Mathematical modelling for conservation and management of gorgonians corals: youngs and olds, could they coexist? Ecol Model 220:2851-2856

Brazeau DA, Lasker HR (1990) Sexual reproduction and external brooding by the Caribbean gorgonian Briareum asbestinum. Mar Biol 104:465-474

Caley MJ, Carr MH, Hixon MA, Huges TP, Jones GP, Menge BA (1996) Recruitment and the local dynamics of open marine populations. Annu Rev Ecol Syst 27: $477-500$

> Cerrano C, Bavestrello G, Bianchi CN, Cattaneo-Vietti R and others (2000) A catastrophic mass-mortality episode of gorgonians and other organisms in the Ligurian Sea (North-western Mediterranean), summer 1999. Ecol Lett 3:284-293

> Cerrano C, Arillo A, Azzini F, Calcinai B and others (2005) Gorgonian population recovery after a mass mortality event. Aquat Conserv 15:147-157

Cerrano C, Danovaro R, Gambi C, Pusceddu A, Riva A, Schiaparelli S (2010) Gold coral (Savalia savaglia) and gorgonian forests enhance benthic biodiversity and ecosystem functioning in the mesophotic zone. Biodivers Conserv 19:153-167

Coma R, Ribes M, Zabala M, Gili JM (1995a) Reproduction and cycle of gonadal development in the Mediterranean gorgonian Paramuricea clavata. Mar Ecol Prog Ser 117: 173-183

Coma R, Zabala M, Gili JM (1995b) Sexual reproductive effort in the Mediterranean gorgonian Paramuricea clavata. Mar Ecol Prog Ser 117:185-192

> Coma R, Ribes M, Zabala M, Gili JM (1998) Growth in a modular colonial marine invertebrate. Estuar Coast Shelf Sci 47:459-470

Coma R, Pola E, Ribes M, Zabala M (2004) Long-term assessment of temperate octocoral mortality patterns, protected vs. unprotected areas. Ecol Appl 14:1466-1478

Coma R, Ribes M, Serrano E, Jiménez E, Salat J, Pascualc J (2009) Global warming-enhanced stratification and mass mortality events in the Mediterranean. Proc Natl Acad Sci USA 106:6176-6181
Crisci C, Bensoussan N, Romano JC, Garrabou J (2011) Temperature anomalies and mortality events in marine communities: insights on factors behind differential mortality impacts in the NW Mediterranean. PLoS ONE 6: e23814

Cupido R (2010) Demography of the red gorgonian Paramuricea clavata (Anthozoa, Octocorallia) damaged by repeated anomalous mortality events. PhD Thesis, University of Pisa

Cupido R, Cocito S, Sgorbini S, Bordone A, Santangelo G (2008) Response of a gorgonian (Paramuricea clavata) population to mortality events: recovery or loss? Aquat Conserv 18:984-992

Cupido R, Cocito S, Barsanti M, Sgorbini S, Peirano M, Santangelo G (2009a) Unexpected long-term population dynamics in a canopy-forming gorgonian following mass mortality. Mar Ecol Prog Ser 394:195-200

Cupido R, Cocito S, Peirano A, Sgorbini S, Santangelo G (2009b) Mortality and resilience: a ten-year monitoring of gorgonian population trends in the Eastern Ligurian Sea (NW Mediterranean). In: Pergent-Martini C, Brichet $\mathrm{M}$ (eds) Proc 1st Medit Symp on the conservation of the coralligenous and other calcareous bio-concretions, Tabarka (Tunisia). RAC/SPA, Tunis, p 82-87

Edmunds JP (2010) Population biology of Porites asteroides and Diploria strigosa on a shallow Carribean reef. Mar Ecol Prog Ser 418:87-104

> Gallmetzer I, Haselmair A, Velimirov B (2010) Slow growth and early sexual maturity: bane and boon for the red coral Corallium rubrum. Estuar Coast Shelf Sci 90:1-10

Garrabou J, Perez T, Sartoretto S, Harmelin JG (2001) Mass mortality event in red coral Corallium rubrum populations in the Provence region (France, NW Mediterranean). Mar Ecol Prog Ser 217:263-272

> Garrabou J, Coma R, Bensoussan N, Chevaldonné P and others (2009) Mass mortality in NW Mediterranean rocky benthic communities: effects of the 2003 heat wave. Glob Change Biol 15:1090-1103

Gili JM, Coma R (1998) Benthic suspension feeders: their paramount role in littoral marine food webs. Trends Ecol Evol 13:316-321

Gori A, Linares C, Rossi S, Coma R, Gili JM (2007) Spatial variability in the reproductive cycle of the gorgonians Paramuricea clavata and Eunicella singularis (Anthozoa, Octocorallia) in the Western Mediterranean Sea. Mar Biol 151:1571-1584

Gotelli NJ (1988) Determinants of recruitment, juvenile growth, and spatial distribution of a shallow-water gorgonian. Ecology 69:157-166

Grigg RW (1988) Recruitment limitation in a deep benthic hard-bottom octocoral population in the Hawaiian Islands. Mar Ecol Prog Ser 45:121-126

Huete-Stauffer C, Vielmini I, Palma M, Navone A, Panzalis P, Vezzulli L, Cerrano C (2011) Paramuricea clavata (Anthozoa, Octocorallia) loss in the Marine Protected Area of Tavolara (Sardina, Italy) due to a mass mortality event. Mar Ecol 32:107-116

> Hughes TP, Connell JH (1987) Population dynamics based on size or age? A reef-coral analysis. Am Nat 129:818-829

> Hughes TP, Jackson JBC (1985) Population dynamics and life histories of foliaceous corals. Ecol Monogr 55: 141-166

Jackson JBC, Hughes TP (1985) Adaptive strategies of coral reef invertebrates. Am Sci 73:265-274

> Lasker HR (1991) Population growth of a gorgonian coral: 
equilibrium and non-equilibrium sensitivity to changes in life history variables. Oecologia 86:503-509

Lasker HR, Kim K, Cofforth MA (1998) Production, settlement and survival of plexaurid gorgonian recruits. Mar Ecol Prog Ser 162:111-123

Leigh EG, Herre EA, Fisher EA (1985) Sex allocation in animals. Experientia 41:1265-1276

Lejeusne C, Chevaldonné P, Pergent-Martini C, Boudouresque $C F$, Pérez $T$ (2010) Climate change effects on a miniature ocean: the highly diverse, highly impacted Mediterranean Sea. Trends Ecol Evol 25:250-260

Linares C (2006) Population ecology and conservation of a long-lived species: the red gorgonian Paramuricea clavata. PhD thesis, University of Barcelona

Linares C, Doak DF (2010) Forecasting the combined effects of disparate disturbances on the persistence of long-lived gorgonians: a case study of Paramuricea clavata. Mar Ecol Prog Ser 402:59-68

Linares C, Coma R, Zabala M (2007a) Effects of a mass mortality event on gorgonian reproduction. Coral Reefs 27: 27-34

Linares C, Doak DF, Coma R, Diaz D, Zabala M (2007b) Life history and viability of a long-lived marine invertebrate: the octocoral Paramuricea clavata. Ecology 88:918-928

Linares C, Coma R, Garrabou J, Díaz D, Zabala M (2008a) Size distribution, density and disturbance in two Mediterranean gorgonians: Paramuricea clavata and Eunicella singularis. J Appl Ecol 45:688-699

Linares C, Coma R, Mariani S, Díaz D, Hereu B, Zabala M (2008b) Early life history of the Mediterranean gorgonian Paramuricea clavata: implications for population dynamics. Invertebr Biol 127:1-11

- Mari L, Gatto M, Casagrande R (2008) Logical resource competition and the skewness of the sex ratios: a demographic model. Math Biosci Eng 5:813-830

Michalek-Wagner K, Willis BL (2001) Impacts of bleaching on the soft coral Lobophytum compactum. I. Fecundity, fertilisation and offspring viability. Coral Reefs 19: 231-239

Mistri M, Ceccherelli VU (1994) Growth and secondary production of the Mediterranean gorgonian Paramuricea clavata. Mar Ecol Prog Ser 103:291-296

Pielou EC (1962) The use of plant to neighbour distances for detection of competition. J Ecol 50:357-367

Editorial responsibility: Hans Heinrich Janssen, Oldendorf/Luhe, Germany
Ribes M, Coma R, Gili JM (1999) Heterogeneous feeding in benthic suspension feeders: the natural diet and grazing rate of the temperate gorgonian Paramuricea clavata (Cnidaria: Octocorallia) over a year cycle. Mar Ecol Prog Ser 183:125-137

Rossi S, Gili JM, Garrofé X (2011) Net negative growth detected in a population of Leptogorgia sarmentosa: quantifying the biomass loss in a benthic soft bottomgravel gorgonian. Mar Biol 158:1631-1643

Santangelo G, Carletti E, Maggi E, Bramanti L (2003) Reproduction and population sexual structure of the overexploited Mediterranean red coral Corallium rubrum. Mar Ecol Prog Ser 248:99-108

- Santangelo G, Bramanti L, Iannelli M (2007) Population dynamics and conservation biology of the over-exploited Mediterranean red coral. J Theor Biol 244:416-423

Scinto A, Bertolino M, Calcinai B, Huete-Stauffer C, Previati M, Romagnoli T, Cerrano C (2009) Role of a Paramuricea clavata forest in modifying the coralligenous assemblages. In: Pergent-Martini C, Brichet M (eds) Proc 1st Medit Symp on the conservation of the coralligenous and other calcareous bio-concretions, Tabarka (Tunisia). RAC/SPA, Tunis, p 136-140

Stearns SC (1997) The evolution of life histories. Oxford University Press, Oxford

Teixido N, Pineda MC, Garrabou J (2009) Decadal demographic trends of a long-lived temperate encrusting sponge. Mar Ecol Prog Ser 375:113-124

Torrents O, Garrabou J (2011) Fecundity of red coral Corallium rubrum (L) populations inhabiting in contrasting environmental conditions in the NW Mediterranean. Mar Biol 158:1019-1028

Tsounis G, Rossi S, Grigg R, Santangelo G, Bramanti L, Gili JM (2010) The exploitation and conservation of precious corals. Oceanogr Mar Biol Annu Rev 48:161-212

Upton G, Fingleton B (1985) Spatial data analysis by example. John Wiley \& Sons, New York, NY

- Van Veghel MLJ, Bak RPM (1994) Reproductive characteristics of the polymorphic Caribbean reef building coral Montastrea annularis. III. Reproduction in damaged and regenerating colonies. Mar Ecol Prog Ser 109:229-233

Weinberg S, Weinberg F (1979) The life cycle of a gorgonian: Eunicella singularis (Esper, 1794). Bijdr Dierk 48: $127-140$

Submitted: September 14, 2011; Accepted: August 1, 2012 Proofs received from author(s): November 12, 2012 